\title{
Predicting percentage of individuals consuming foods from percentage of households purchasing foods to improve the use of household budget surveys in estimating food chemical intakes
}

\author{
Joyce Lambe ${ }^{1}$, John Kearney ${ }^{1, *}$, Wulf Becker ${ }^{2}$, Karin Hulshof ${ }^{3}$, Adrian Dunne ${ }^{4}$ and \\ Michael J Gibney' \\ ${ }^{1}$ Institute of European Food Studies, Trinity College, Dublin 2, Ireland: ${ }^{2}$ National Food Administration, \\ Box 622, 5-751 26, Uppsala, Sweden: ${ }^{3}$ TNO Nutrition and Food Research Institute, Utrechtseweg \\ 48, PO Box 360, 3700 A Zeist, The Netherlands: ${ }^{4}$ Department of Statistics, University College \\ Dublin, Belfield, Dublin 4, Ireland
}

Submitted 12 Morch 1998: Accepted 20 July 1998

\begin{abstract}
Objective: To examine the hypothesis that there is sufficient agreement between percentage of households purchasing selected foods using household budget surveys and percentage of individuals consuming these foods as determined in individualbased surveys to allow the former to act as a surrogate for the latter when estimating food chemical intakes using household budget data.

Design: Database study.

Setting: Databases from Sweden, The Netherlands, Ireland and the UK.

Subjects: 319 foods (Sweden $n=60$, The Netherlands $n=80$, Ireland $n=90$, UK $n=89$ ).

Results: Pearson correlations demonstrated a high degree of linear association between $\%$ households purchasing and \% consumers $(r=0.86)$. Regression analysis defined a close positive relationship between the two datasets (slope 0.95, intercept +2.74 ). Across countries, using the regression equation, the $\%$ households predicted $\%$ consumers to within $5 \%$ of the true value for between 33 and $48 \%$ of foods and to within $10 \%$ for between 53 and $78 \%$ of foods.

Conclusions: Values for \% households can be used as a crude surrogate for $\%$ consumers and can thus play a role in improving estimates of food additive intake.
\end{abstract}

\author{
Kerwords \\ Househald budget surveys \\ Food chemical intake estimation
}

Monitoring national food consumption is an integral part of any national food policy, providing data for the estimation of nutrient intake and food chemical intake. The demand for good food intake data for monitoring food chemical intake is ever increasing, with risk assessments now required for food additives, pesticide residues, contaminants, food packaging material migrants, natural plant toxicants and so forth. Many options are available in considering suitable methodologies for measuring food consumption data: prospective versus retrospective methods, quantitative versus qualitative, direct versus indirect and individual versus household. Household budget and household inventory surveys provide detailed information on food purchases at the level of the household which may then be used to provide an indirect estimate of food consumption using appropriate conversion factors ${ }^{1}$. These surveys may collect information solely on the amount of money spent on various commodities or on the amount of money spent plus the quantity purchased. Where only expenditure data are collected, a price index can be used to transform these economic data into estimates of food quantities ${ }^{2}$. Household surveys are attractive to many countries where resources may not be available for conducting a large individual-based food consumption survey.

Notwithstanding the fact that the data are collected at household level, several statistical models have attempted to provide reliable derivatives of food and nutrient intake for specific age and sex groups $^{3-5}$. For the purposes of food chemical monitoring, however, mean intakes of foods among the total population or population subgroups are not sufficient. Because the aim is to determine the exposure to a food chemical, the assessment must focus on the intakes of the individuals eating the food(s) in question and particularly those with the highest intake of the food(s). At present, it is not possible with household survey data to estimate the intake of a given food among consumers only of that food because household surveys do not provide data on the food intake among individuals 
within the household. Household survey intakes, therefore, represent the intake of the total population, i.e. consumers and non-consumers.

The significance of this for food chemical intake can be seen with the following example. If a given food chemical is present in food A with a mean population intake of $\mathrm{P}\left(\mathrm{g} \mathrm{day}^{-1}\right)$ and with $\mathrm{C} \%$ consumers, then the intake of $\mathrm{A}$ among consumers only $\mathrm{CO}\left(\mathrm{g} \mathrm{day}^{-1}\right)$ is $100 \times \mathrm{P} / \mathrm{C}$. Clearly, the nearer $\mathrm{C}$ is to $100 \%$, the closer $\mathbf{P}$ and $\mathrm{CO}$ are. However, for foods consumed by, for example, $33 \%$ of the population, $\mathrm{CO}$ is three times $\mathrm{P}$. Thus in the absence of data on $\mathrm{C}$, an inevitability with the household method is that the estimate of food chemical intake will tend to underestimate true consumer intakes of the chemical in question. The present paper examines the hypothesis that there is sufficient agreement between \% households purchasing given foods using household budget surveys and $\%$ individuals consuming these foods as determined in individual-based surveys to allow the former to act as a surrogate for the latter when estimating food chemical intake using household budget survey data.

\section{Materials and methods}

Four countries participated in the study where each country had both a household survey and an individual-based survey from the same time period. Table $1 \mathrm{a}$ and $1 \mathrm{~b}$ summarize the structure of the parallel databases in each country. Each participating centre was asked to identify $70-80$ foods or food groups for which consumption/purchase data existed in both the household and individual survey databases. Whilst there was considerable overlap between centres, certain suitable foods found on both databases in one centre may not have been present in all others and where food groupings rather than foods were the database-listed item, the exact food group definitions sometimes varied. Thus whereas the Irish database allowed comparisons to be made for 15 meat and poultry listings, the Swedish database allowed only six comparisons within the category. These variations across centres do not in any way detract from the capacity of each centre to test the hypothesis in question, rather they add to it by providing heterogeneity. In choosing suitable foods, each centre was asked to include both rarely and commonly eaten foods, foods which are consumed as the whole product (e.g. cakes) and foods which are more commonly used as ingredients in composite dishes (e.g. onions), and quite specifically defined foods (e.g. white bread) in addition to more aggregated food groups (e.g. all breads). For each food, the \% households purchasing and the $\%$ individuals consuming were estimated for each centre. In The Netherlands, the analysis was run based on adults only from the individual survey and adult only households from the household survey. In both Sweden and the UK an analysis of adult only data was conducted in addition to an analysis of the total samples from the parallel databases but the results presented refer to the total sample. In Ireland, it was not possible to separate households on the basis of adults only and therefore the results refer to comparison of all individuals with all households.

The percentages of households purchasing each food were plotted against the values for $\%$ consumers of these foods. Pearson correlation coefficients were calculated as a summary measure of the strength of the association between the two datasets. The individual data were regressed on the household data to derive the best fitted line. This was done for each centre and for the four centres combined as well as for certain aggregated food groups based on the combined datasets. The degree of variation between $\%$ consumers of foods and \% households purchasing the same foods was determined by estimating the prediction errors for each food ${ }^{6}$. This entailed regressing individual data on household data, leaving out on each occasion the food for which the prediction error was to be derived. The equation so derived was then used to estimate \% individuals consuming (Ye) from the \% households purchasing the food in question. This was compared with the actual \% individuals consuming (Ya) and the prediction error was calculated as the difference between the actual and the estimated ( $\mathrm{Ya}-\mathrm{Ye}$ ). Prediction errors may be positive (underestimate \% consumers) or negative (overestimate \% consumers). A summary measure, the root mean square error (RMSE) ${ }^{6}$, was used to make comparisons of prediction errors between countries and regularity of purchase of foods. The RMSE was calculated for each country by squaring the prediction error for each food, calculating the mean of the squared prediction errors within each country and then calculating the square root of these values. The RMSEs were then compared between countries. To assess the influence of regularity of purchase on the accuracy of predicting $\%$ consumers, the foods from the merged dataset from all countries ( $n=319$ ) were classified into rarely purchased foods purchased by less than $10 \%$ of households $(n=65)$, quite commonly purchased foods purchased by $30-70 \%$ of households $(n=115)$ and very commonly purchased foods purchased by more than $80 \%$ of households $(n=11)$. The RMSEs were calculated by squaring the prediction errors for each food item classified as rarely, quite commonly or very commonly purchased, calculating the mean of the squared prediction errors within each classification and then calculating the square root of these values. 
Table 1(a) Details of the household budget surveys for the four centres

\begin{tabular}{|c|c|c|c|c|}
\hline & Sweden & Netherlands & UK & Ireland \\
\hline Survey name & $\begin{array}{l}\text { Hushallens } \\
\text { Livsmedelsutgifter }\end{array}$ & $\begin{array}{l}\text { Dutch Household Budget } \\
\text { Survey } 1992\end{array}$ & $\begin{array}{l}1988 \text { National Food } \\
\text { Survey }\end{array}$ & $\begin{array}{l}1987 \text { Household Budget } \\
\text { Survey }\end{array}$ \\
\hline Agency responsible & $\begin{array}{l}\text { Statistics Sweden, } \\
\text { Stockholm }\end{array}$ & Central Bureau of Statistics & $\begin{array}{l}\text { Ministry of Agriculture, } \\
\text { Fisheries and Food }\end{array}$ & Central Statistics Otfice \\
\hline Sample size & 2079 households & 1967 households & 7318 households & 7705 households \\
\hline Age range & All ages & All ages & All ages & All ages \\
\hline Typology of data & $\begin{array}{l}\text { Foods purchased, } \\
\text { expenditure and } \\
\text { amounts }\end{array}$ & $\begin{array}{l}\text { Foods purchased, } \\
\text { expenditure only }\end{array}$ & $\begin{array}{l}\text { Foods purchased, } \\
\text { expenditure and } \\
\text { amounts }\end{array}$ & $\begin{array}{l}\text { Foods purchased, } \\
\text { expenditure only }\end{array}$ \\
\hline Survey method & 4-week purchase records & 7-day purchase records & $\begin{array}{l}\text { 7-day purchase } \\
\text { records }\end{array}$ & 7-day purchase records \\
\hline $\begin{array}{l}\text { Foods eaten outside } \\
\text { the home }\end{array}$ & $\begin{array}{l}\text { Expenditure for meals } \\
\text { eaten outside the home }\end{array}$ & $\begin{array}{l}\text { Expenditure for meals } \\
\text { eaten outside the home }\end{array}$ & $\begin{array}{l}\text { Number of meals but } \\
\text { not cost or content }\end{array}$ & $\begin{array}{l}\text { Expenditure for meals } \\
\text { eaten outside the home }\end{array}$ \\
\hline $\begin{array}{l}\text { Number of food } \\
\text { items* }\end{array}$ & Approx. 400 & Approx. 375 & Approx. 180 & Approx. 125 \\
\hline Published data & $\begin{array}{l}\text { 1992: Household } \\
\text { expenditures } 1989 \text { with } \\
\text { amounts (in Swedish) }\end{array}$ & $\begin{array}{l}\text { 1992: Budget Survey } \\
\text { (in Dutch) }{ }^{10}\end{array}$ & $\begin{array}{l}1988 \text { Household Food } \\
\text { Consumption and } \\
\text { Expenditure }{ }^{11}\end{array}$ & $\begin{array}{l}1987 \text { Household Budget } \\
\text { Survey }{ }^{12}\end{array}$ \\
\hline
\end{tabular}

- Refers to the number of food iterns for which purchase data existed in the databases analysed.

\section{Results}

In total, 319 foods were included in the analysis -60 foods from Sweden, 80 foods from The Netherlands, 90 foods from Ireland and 89 foods from the UK (see Appendix). The results of the Pearson correlations and regression analysis are given in Table 2 . The Pearson correlations demonstrate a high degree of linear association between the two datasets. The regression analysis defined a close positive relationship, with the slopes of the lines approaching 1 and the intercepts approaching 0 . The relationship between the two datasets is illustrated for all four centres combined in Fig. 1. When specific food groups were considered across countries, although several retained the features for all foods compared within a country

Table 1(b) Details of the individual surveys for the four centres

\begin{tabular}{|c|c|c|c|c|}
\hline & Sweden & Netherlands & UK & Ireland \\
\hline Survey name & $\begin{array}{l}\text { Och Kostvanor } 1989 \\
\text { (HULK) }\end{array}$ & $\begin{array}{l}\text { Dutch National Food } \\
\text { Consumption Survey } \\
1992\end{array}$ & $\begin{array}{l}\text { Dietary and Nutritional } \\
\text { Survey of British } \\
\text { Adults } 1988\end{array}$ & $\begin{array}{l}\text { Irish National Nutrition } \\
\text { Survey } 1990\end{array}$ \\
\hline Agency responsible & $\begin{array}{l}\text { National Food } \\
\text { Administration, Uppsala }\end{array}$ & $\begin{array}{l}\text { Ministry of Health, Welfare } \\
\text { and Sport; Ministry of } \\
\text { Agriculture, Nature } \\
\text { Management and Fisheries }\end{array}$ & $\begin{array}{l}\text { Ministry of Agriculture } \\
\text { Fisheries and Food }\end{array}$ & $\begin{array}{l}\text { Irish Nutrition and } \\
\text { Dietetic Institute }\end{array}$ \\
\hline Sample size & 2047 individuals & 6218 individuals & 2197 individuals & 1218 individuals \\
\hline Age range & $1-74$ years & 1 yeart & $16-64$ years & 8 years + \\
\hline Typology of data & Foods consumed & Foods consumed & Foods consumed & Foods consumed \\
\hline Survey method & 7-day food record & 2-day food record & 7-day weighed record & 7-day diet history \\
\hline $\begin{array}{l}\text { Foods eaten } \\
\text { outside the home }\end{array}$ & $\begin{array}{l}\text { All foods consumed at } \\
\text { home and outside the } \\
\text { home }\end{array}$ & $\begin{array}{l}\text { Main housekeeper recorded } \\
\text { all foods eaten at home for } \\
\text { each individual and subject } \\
\text { recorded foods eaten } \\
\text { outside the home }\end{array}$ & $\begin{array}{l}\text { All foods consumed } \\
\text { at home and outside } \\
\text { the home }\end{array}$ & $\begin{array}{l}\text { All foods consumed at } \\
\text { home and outside the } \\
\text { the home }\end{array}$ \\
\hline $\begin{array}{l}\text { Number of food } \\
\text { items* }\end{array}$ & Approx. 500 & Approx. 1100 & Approx. 3850 & Approx. 700 \\
\hline Published data & $\begin{array}{l}\text { 1994: Dietary Habits } \\
\text { Sweden } 1989 \\
\text { (in Swedish) }\end{array}$ & Zo eet Nederland $1992^{14}$ & $\begin{array}{l}\text { Dietary and Nutritional } \\
\text { Survey of British } \\
\text { Adults } 1988^{15}\end{array}$ & $\begin{array}{l}\text { Irish National Nutrition } \\
\text { Survey } 1990^{16}\end{array}$ \\
\hline
\end{tabular}

"Refers to the number of food codes for which consumption data existed in the databases analysed. 
Table 2 Constants and slopes for the regression equation: $\%$ individuals consuming $=b$ (\% households) $+a$, for all foods within a country and for nine food groups across countries, together with Pearson correlation coefficients $(r)$ and significance levels $(P)$

\begin{tabular}{lcccc}
\hline & Slope $(b)$ & Constant $(a)$ & $r$ & $P$ \\
\hline Within countries & & & & \\
Sweden $(n=60)$ & 0.95 & +5.69 & 0.84 & 0.000 \\
The Netherlands $(n=80)$ & 0.93 & +1.93 & 0.81 & 0.000 \\
Ireland $(n=90)$ & 0.89 & -1.11 & 0.93 & 0.000 \\
UK $(n=89)$ & 1.16 & +3.33 & 0.86 & 0.000 \\
All four centres combined $(n=319)$ & 0.95 & +2.74 & 0.86 & 0.000 \\
Within food groups & & & & \\
Bread & 1.03 & +2.86 & 0.85 & 0.000 \\
Cereals & 1.05 & +5.55 & 0.88 & 0.001 \\
Cakes and buns & 0.63 & +21.71 & 0.49 & 0.150 \\
Dairy products & 0.86 & +3.70 & 0.89 & 0.000 \\
Meat & 1.04 & -0.89 & 0.87 & 0.000 \\
Fish & 1.01 & -0.64 & 0.89 & 0.000 \\
Fruit & 0.86 & +2.85 & 0.95 & 0.000 \\
Vegetables & 0.97 & +2.85 & 0.80 & 0.000 \\
Savoury snacks & 0.66 & +6.55 & 0.65 & 0.040 \\
\hline
\end{tabular}

(i.e. slope almost 1 and intercept approaching 0), two in particular deviated i.e. 'cakes and buns' and 'savoury snacks' with slopes of 0.63 and 0.66 , respectively, and intercepts of +21.71 and +6.55 , respectively. Possible reasons why actual \% consumers of these food groups were significantly higher than the predicted values are considered in the discussion section of this paper. Table 3 gives data on prediction errors. Just under half of the foods in the analysis had positive prediction errors, indicating that the values for $\%$ households purchasing underestimated \% consumers, with the remainder of the foods having negative prediction errors and thus overestimating \% consumers. Between 33 and $48 \%$ of the foods had very low prediction errors ( \pm ) $5 \%$, with $53-78 \%$ of foods being predicted to within $10 \%$ of the actual value. The RMSE values

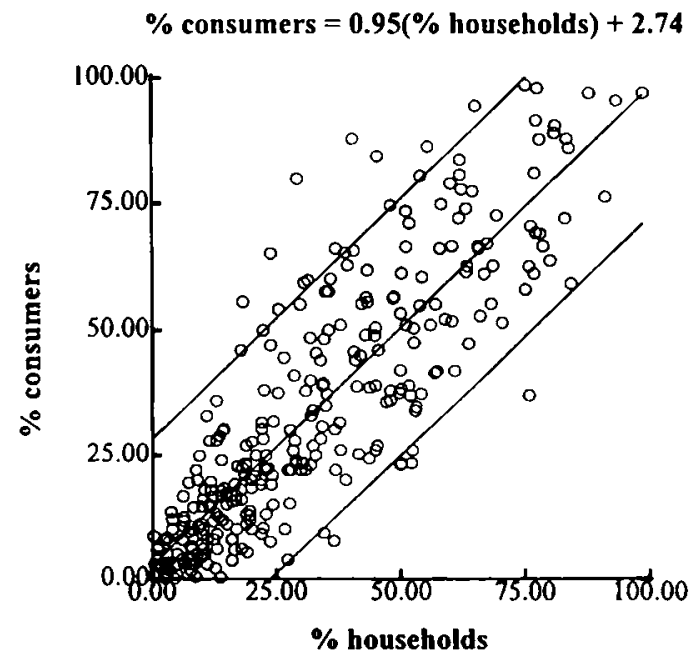

Fig. 1 Regression line with $95 \%$ prediction intervals for $\%$ households regressed on $\%$ individuals for all foods $(n=319)$ for Sweden, The Netherlands, Ireland and the UK combined ranged from 10 to $15 \%$ between countries. This indicates that in Ireland, the estimated value for $\%$ consumers based on \% households was, on average, $\pm 10 \%$ of the actual value. In Sweden, the RMSE value was $\pm 15(\%)$, reflecting larger differences between the actual and estimated values. Table 4 considers prediction errors for foods which were rarely purchased (i.e. purchased by $>10 \%$ of households), quite commonly purchased (30-70\% of households) and very commonly purchased ( $>80 \%$ of households). The majority of foods were within the $( \pm) 10 \%$ range. Some $75 \%$ of rarely purchased foods were predicted to within $5 \%$ of the true value, while none of these foods exceeded a $15 \%$ prediction error. In the other two food categories about a quarter of foods were at the higher end of the prediction error range. The influence of regularity of purchase of foods is summarized in the RMSE values, with the rarely purchased foods showing a smaller average difference between the actual values when compared with more commonly purchased foods (Table 4).

\section{Discussion}

The results of the present study form a considered and logical basis whereby those confined to using household survey data can confidently predict, with the use of the regression equation, that $\%$ households purchasing a given food will give a meaningful crude estimate of \% individuals eating that food, which in turn provides them with the ability to determine the mean intake of the food among consumers only. A multiple of 3 times the mean intake among consumers is accepted as a crude indicator of intake at the 95th percentile ${ }^{7}$ and thus can provide information about intakes at the upper extremes of consumption which are of most relevance for risk assessment. Clearly 
Table 3 Percentage of foods with positive or negative prediction errors in comparing predicted $\%$ consumers based on households purchasing with actual \% consumers, the distribution of prediction errors and root mean square errors for each centre

\begin{tabular}{lcccr}
\hline & Sweden & Netherlands & Ireland & UK \\
\hline \% Foods with & & & & \\
+ ve prediction error & 52 & 38 & 46 & 43 \\
- ve prediction error & 48 & 62 & 54 & 57 \\
\% Foods with prediction errors in the range & & & & \\
$( \pm) 5 \%$ & 33 & 40 & 42 & 48 \\
$( \pm) 5-10 \%$ & 20 & 30 & 36 & 25 \\
$( \pm) 10-15 \%$ & 13 & 15 & 12 & 11 \\
$( \pm)>15 \%$ & 34 & 15 & 10 & 16 \\
Root mean square error & 15 & 12 & & 13 \\
\hline
\end{tabular}

therefore, the ability to predict \% consumers greatly enhances the use of household data in risk assessment exercises, particularly for estimating food additive intake or the intake of novel food ingredients. To illustrate this improvement we use Swedish food consumption data and a hypothetical example of an additive permitted in ice cream (Table 5). The consumers only intake refers to the intake among consumers of ice cream calculated using the Swedish individual-based food consumption survey and thus is a suitable value on which to base a risk assessment. Scenarios 1, 2 and 3 consider estimates of intake where no individual-based survey is available and household data are used. In scenario 1, the mean total population intake (total purchase of ice cream/total sample) provided by the household budget survey is used. As it stands, however, it underestimates the additive intake by $50 \%\left(7 \mathrm{mg} \mathrm{day}^{-1}\right.$ vs. $\left.14 \mathrm{mg} \mathrm{day}^{-1}\right)$. In scenario 2 , a 'consumers only' estimate is derived from the household budget survey mean total population intake. This is done by dividing the mean total population intake by the ' $\%$ consumers' value estimated by inserting the value for $\%$ households purchasing ice cream (54.3\%) into the regression equation. This refines the estimate of intake of additive $\mathrm{X}$ to $13 \mathrm{mg} \mathrm{day}^{-1}$, a value almost identical to that given by the individualbased survey. Because of the very close relationship which was observed when $\%$ individuals were regressed on \% households (slope approaching 1 and intercept approaching 0), a third scenario was considered which used the value of $\%$ households as a direct substitute for $\%$ individuals, i.e. do not use a regression equation. This method also gives an estimate of $13 \mathrm{mg} \mathrm{day}^{-1}$. Therefore, in this example, the degree of underestimation which arises with the use of mean total population intakes from household surveys has been dramatically reduced by using \% households, either directly or through the regression equation, to substitute for \% consumers. The significance of being able to estimate \% consumers and consumer only intakes rather than just mean total population intakes is evident from the fact that in the present study $34 \%$ of foods were consumed by $<10 \%$ of individuals. Thus the household estimate of intakes of foods would contain about 1 in 3 foods, the intakes of which are an order of magnitude greater among consumers of these foods.

In the present study we also sought to investigate factors which may influence how well \% households purchasing different foods predicted $\%$ consumers of these foods. One consideration was comparability of the sample characteristics between the parallel databases within each country. Household surveys record food purchase data for the entire household whereas some individual surveys may only record the food intakes for a selected age range in the

Table 4 The distribution of prediction errors across centres for foods 'rarely', 'quite commonly' and 'very commonly' purchased together with their root mean square error

\begin{tabular}{lccc}
\hline & $\begin{array}{c}\text { Rarely purchased } \\
(n=65)\end{array}$ & $\begin{array}{c}\text { Quite commonly purchased } \\
(n=115)\end{array}$ & $\begin{array}{c}\text { Very commonly purchased } \\
(n=11)\end{array}$ \\
\hline \% Foods with prediction errors in the range & 75 & 26 & 45 \\
$( \pm) 5 \%$ & 20 & 30 & 18 \\
$( \pm) 5-10 \%$ & 5 & 17 & 10 \\
$( \pm) 10-15 \%$ & 0 & 26 & 27 \\
$( \pm)>15 \%$ & 4.7 & 14.8 & 10.2 \\
Root mean square error & & \\
\hline
\end{tabular}

"Rarely purchased, quite commonly purchased and very commonly purchased were defined as foods purchased by $<10 \%, 30-70 \%$ and $>80 \%$ of households, respectively. 
Table 5 Example of improving the usefulness of household budget data for estimating food chemical intakes, based on Swedish data. Additive $X$ permitted in ice cream at $0.5 \mathrm{~g} \mathrm{~kg}^{-1}$

\begin{tabular}{|c|c|c|c|}
\hline & $\begin{array}{l}\text { Ice cream } \\
\text { consumption } \\
\left(\text { g day }^{-1}\right)\end{array}$ & $\begin{array}{l}\text { Assumed additive } \\
\text { concentration } \\
\left(\mathrm{mgg}^{-1}\right)\end{array}$ & $\begin{array}{c}\text { Estimated additive } \\
\text { intake } \\
\left.\text { (mg day }^{-1}\right)\end{array}$ \\
\hline $\begin{array}{l}\text { Actual intake } \\
\text { Consumers only }\end{array}$ & 28 & 0.5 & 14 \\
\hline $\begin{array}{l}\text { Scenario } 1 \\
\text { Mean total population }\end{array}$ & 14 & 0.5 & 7 \\
\hline $\begin{array}{l}\text { Scenario } 2 \\
\text { Mean total population corrected for } \% \mathrm{HH} \text { purchasing } \\
\text { calculated using regression equation }\end{array}$ & 26 & 0.5 & 13 \\
\hline$\left[\frac{\text { mean total population } \times 100}{0.95(54.3)+2.74}\right]$ & & & \\
\hline $\begin{array}{l}\text { Scenario } 3 \\
\text { Mean total population corrected for \% } \mathrm{HH} \text { purchasing }(54.3 \%)\end{array}$ & 26 & 0.5 & 13 \\
\hline
\end{tabular}

population, e.g. adults only. As highlighted in Tables 1a and $1 \mathrm{~b}$, the individual surveys in both Sweden and The Netherlands cover approximately the same age ranges as the household surveys. In Ireland, the individual survey has data for subjects aged 8 years and upwards and in the UK the individual survey is based on adults only, aged 16-64 years. Neither the Irish nor the British individual surveys could therefore be said to be directly comparable to their respective household surveys in terms of subject characteristics. A subanalysis of adults only \% consumers versus adult only households in the UK, however, showed that making the samples more comparable yielded very little change to either the regression equations or correlation coefficients defining the relationship of $\%$ consumers and \% households purchasing (adults only: $\%$ consumers $=1.23$ ( $\%$ households $)+3.43$, $r=0.86$ ). Comparisons were made between rarely and commonly purchased foods. The vast majority (75\%) of rarely purchased foods (34\% of all foods) are very accurately predicted, i.e. to within $5 \%$. In the case of food additives, this is encouraging since it is the more rarely purchased foods, rather than the commonly purchased foods (e.g. milk and potatoes), which contain additives.

Other potential contributory factors to the larger prediction errors which are proposed by the authors include home-baking, bulk purchase of foods and foods eaten outside the home. For example, in Sweden while only $45 \%$ of households surveyed recorded purchases of cakes and buns, almost $85 \%$ of individuals in the food consumption survey recorded eating these foods. The discrepancy may be attributed to the widespread practice of home baking in Sweden. Conversely, one might expect to see higher values for $\%$ households purchasing ingredient-type foods than $\%$ consumers of those foods. Difficulties for resolving the issue of ingredient-type foods do exist, however, not least because recipe data are not available for all individual survey databases and purchased foods such as flour or cornflour may be used in a wide range of home-cooked composite dishes. Also, ingredienttype foods will vary from one country to another due to different cooking and purchasing practices. Certain commonly eaten foods, while purchased by the majority of households, may be purchased in bulk on an irregular basis. A 7-day purchase record may not 'catch' purchasers of foods which are only purchased once every 2 or 3 weeks, even if these foods are commonly eaten. For example, potatoes, which are outliers in each of the four countries, are also commonly eaten in the home in each of the countries. The reason why the \% purchasers is less than expected is probably simply a reflection of the fact that potatoes may not be purchased on a weekly basis because they are usually purchased in bulk. The same may be true of tea, coffee and certain alcoholic drinks.

In household surveys, account is not usually taken of the expenditure outside the home and therefore a true picture of purchase/intake cannot be obtained for foods which are predominantly purchased outside of the home. For example, this methodological issue may account for the weaker relationship between household and individual data for the food group of 'savoury snacks' as shown in Table 2. Similar considerations were proposed by Nelson et $a l^{8}$, to account for the differences which they found between nutrient intakes estimated from household and individual-based surveys. It was, however, evident from the present study (data not presented) that whilst these influences appeared partly to explain a tendency towards higher prediction errors, there was no consistency across countries. When foods with a prediction error $>15 \%$ were considered, only one food (potatoes) was found to be common to all four countries. Spreadable fats plus oils had a prediction error greater 
than $15 \%$ in three countries. Thus it is necessary that, for each occasion the approach outlined in this paper to derive an estimate for $\%$ consumers is used, local expert knowledge be applied in reaching a judgement in risk assessment.

Further research would be necessary before specific guidelines for judging the accuracy of prediction of $\%$ consumers could be developed. The remit of this study, however, was to examine the possibility of using household data to act as a crude surrogate for individual data, where individual surveys do not exist. In the absence of such a surrogate, the only information provided by household surveys will be mean total population intakes which will inevitably underestimate consumer only intakes. In any analysis, consideration should also be given to the aspects of recording in the household survey which may overestimate the mean total population intake ${ }^{4}$, the value to which the estimate of $\%$ consumers would be applied to obtain an estimate of intake among consumers only. Nonetheless, the approach outlined in this paper greatly improves the use of household data in estimating food chemical intake. Its value in nutrition policy areas should also be considered. Household data are frequently the only source of data for nutrition policy planning. If successive household survey data show a static level of population intake of a food (consumers and non-consumers combined), this could be due to changes in opposite directions between \% consumers and intakes among consumers only, i.e. more people eating slightly less or less people eating slightly more. Thus by using \% households purchasing as a surrogate for $\%$ individuals consuming given foods, more data of nutritional significance can be extracted from household surveys.

\section{References}

1 Kohlmeier L. Problems and pitfalls of food to nutrient conversion in food and health data: their use in nutrition policy making. In: Becker W, Helsing E, eds. WHO: WHO Regional Publications, European Series, 1990; 34: 73-84.

2 Friel $S$, Kelleher $C$ and the DAFNE II group. Use of the Irish household budget survey for food availability estimation. Proc. Nutr. Soc. 1998, 57: 24A.

3 Nelson $M$. The distribution of nutrient intake within families. Br. J. Nutr. 1986; 55: 267-77.

4 Zintaras E, Kanellou A, Trichopoulou A, Nelson M. The validity of household budget survey (HBS) data: estimation of individual food availability in an epidemiological context. J. Hum. Nutr. Dietet. 1997; 10: 53-62.

5 Chesher A. Household composition and household purchases. In: Slater JM, ed. Fifty Years of the National Food Survey. London: Ministry of Agriculture, Fisheries and Food, 1991.

6 Larson HJ. Introduction to Probability Theory and Statistical Inference, third edition. New York: Wiley, 1982.

7 WHO. Guidelines for the study of dietary intakes of chemical contaminants. WHO Offset Publication no. 87. Geneva: World Health Organization, 1985.

8 Nelson M, Dyson PA, Paul AA. Family food purchases and home food consumption: comparison of nutrient contents. Br. J. Nutr. 1985; 54: 373-87.

9 Statistics Sweden. Housebold Expenditures 1989 with Amounts (in Swedish). Stockholm: Statistics Sweden, 1992.

10 Netherlands Central Bureau of Statistics. Budget Survey 1992. Den Haag: SDU Publications, 1992.

11 Ministry of Agriculture, Fisheries and Food. Housebold Food Consumption Survey. London: HMSO, 1988.

12 Central Statistics Office 1987. Housebold Budget Survey. Dublin: Central Statistics Office, 1989.

13 Becker W. Food Habits and Nutrient Intakes in Sweden (in Swedish). Uppsala: National Food Administration, 1994.

14 Anonymous. Zo eet Nederland 1992. Den Haag: Voorlichtingsbureau voor de Voeding, 1993.

15 Gregory J, Foster K, Tyler H, Wiseman M. The Dietary and Nutritional Survey of British Adults. London: HMSO, 1990.

16 Lee P, Cunningham K. Irish National Nutrition Survey. Dublin: Irish Nutrition and Dieteric Institute, 1990. 


\section{Appendix}

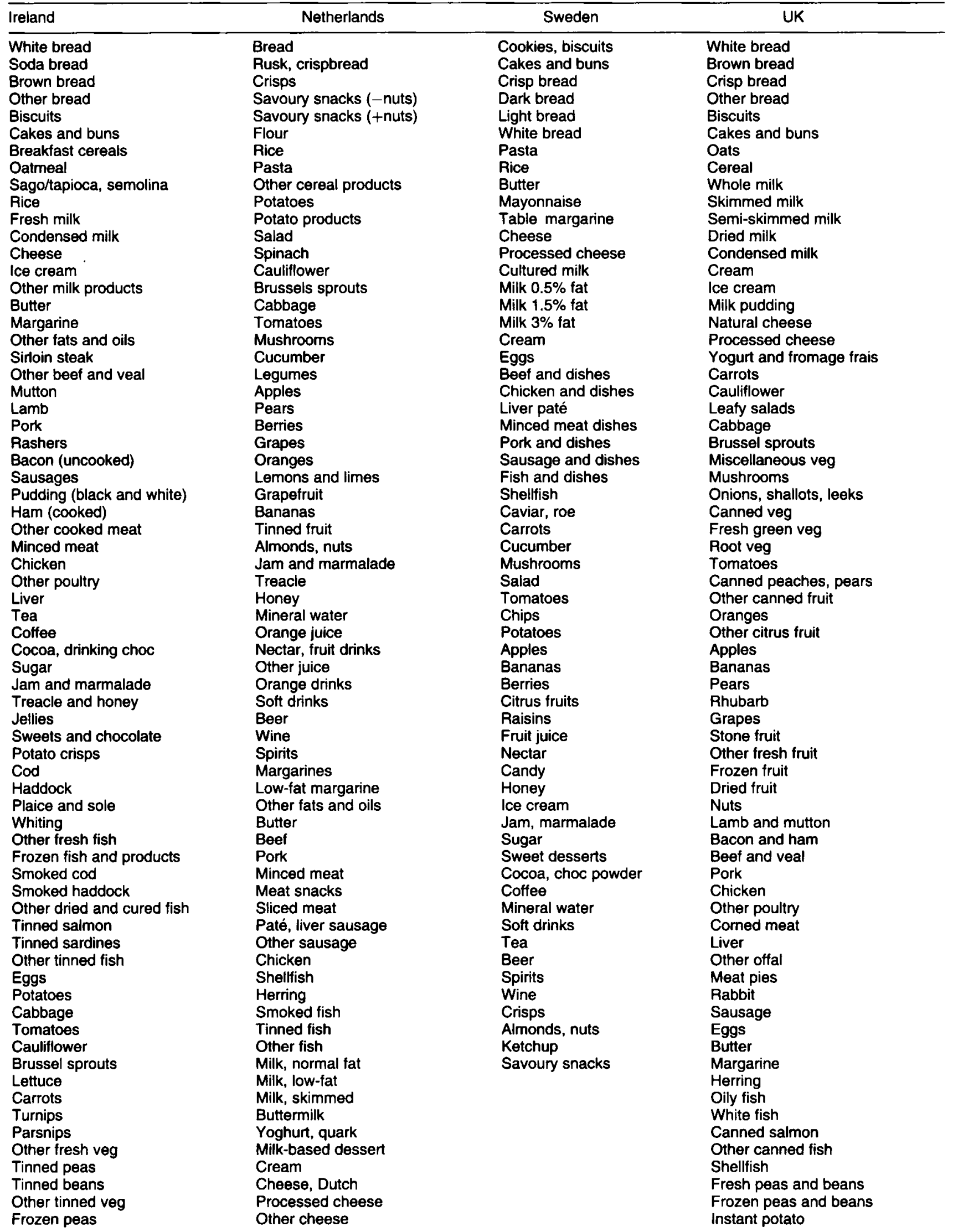




\begin{tabular}{lll}
\hline Ireland & \multicolumn{1}{c}{ Netherlands } & Sweden \\
\hline Frozen potatoes & Ice cream & UK \\
Apples, eating & Ready to eat meals & Canned potato \\
Apples, cooking & Eggs & Potatoes \\
Oranges & Sugar & Chips \\
Bananas & Chocolate flakes, spreads & Canned tomatoes \\
Grapefruit & Other sweet fillings & Turnip \\
Plums & Confectionery & Cucumber \\
Grapes & Chocolate bars & Cocoa \\
Strawberries & Cocoa, chocolate powder & Coffee \\
Other fresh fruit & Tomato ketchup & Tea \\
Tinned peaches & Mayonnaise, dressings & Fruit juice \\
Tinned pears & & Vegetable juice \\
Tinned strawberries & & Pickles and sauces \\
Other tinned fruit & & Soups \\
Other dried fruit and nuts & & Sugar \\
Fruit and vegetable juice & & Syrup and treacle \\
Tinned soup & & Honey \\
Packet soup & & Jam \\
Sauces and creams & & Marmalade \\
Custard and blancmange & & Canned peas and beans \\
Fresh cream & & \\
\hline
\end{tabular}

